\title{
DEVIR-BRASIL: ORALIZAÇÃO DA LITERATURA
}

\author{
Luciano Barbosa Justino ${ }^{1}$
}

Resumo: Meu objetivo neste artigo é fazer um duplo movimento: 1 . Demonstrar que a autonomia da literatura não é mais possível no contexto contemporâneo e 2. Compreender a literatura contemporânea como um espaço aberto para uma multiplicidade de formas de vida.

Palavras-Chave: Autonomia, Literatura, Multiplicidade.

Abstract: My aim in this article is to do two complementary movements: 1 . Demonstrate that the autonomy of literatura is not more possible in the contemporary age and 2. Comprehend as contemporary literature is the open space for a multiplicity of human life.

Keywords: Autonomy, Literature, Multiplicity.

\section{PÓS-AUTONOMIA NA MULTIPLICIDADE}

Se na América Latina em geral e no Brasil em particular estamos diante de um novo ciclo de produção e circulação de bens culturais, a literatura, os “bens literários”, insere-se num estágio “novo” da distribuição e dos modos de validação da cultura que modifica a utilização dos textos, inclusive os ditos literários.

1 Docente do Programa de Pós-Graduação em Literatura e Interculturalidade, Universidade Estadual da Paraíba (PPGLI/UEPB). Pesquisador do CNPq. Endereço eletrônico: lucianobjustino@hotmail.com. 
Pode-se pensar em 2 postulados sobre literatura e cultura no mundo de hoje:

1. Todo bem cultural e literário é econômico, ou seja, está inserido na materialidade das relações de troca e transporte, fazendo muitos ecos. A cultura assume seu estatuto de “coisa num mercado”, ou atravessando vários deles.

2. Todo bem cultural e literário encontra cotidiano saturado de máquinas de produção de linguagem, cujo enriquecimento do mundo da cultura e dos signos embota, com tantos dizeres, toda suposta transparência do real, de imago e de som, de escrita e outras semioses significantes. As metáforas da velha babel estão na ordem do dia.

Parte considerável dos textos que se produzem hoje sob o rótulo de literatura não podem ser reduzidos a uma leitura literária. São estes que mais me interessam. Muitos deles sequer admitem uma "literaturização", aquele acordo tácito entre literariedade e supremacia dos problemas de linguagem, sobretudo da tensão entre ficção e realidade.

A esta configuração entre escrita e cultura, que estou chamando de "nova”, Josefina Ludmer (2007) sugere a expressão “Literaturas pós-autônomas”.

São narrativas e formas poéticas que perfazem outros movimentos de produção de sentido, aos quais Josefina Ludmer chama de "práticas literárias territoriais do cotidiano" (LUDMER, 2007, p. 11), em que a linkagem estreita vida/obra, sem crise e culpa, toma a dianteira e não mais a função autor-obra no chamado Campo literário, embora a "velha” e modernista relação não deixe de ser pertinente por completo.

O auto-instituir-se da literatura parte do pressuposto da autonomia do espaço literário, regido por leis que têm suas próprias lógicas de produção, circulação e consumo. Importa na autonomia de campo compreender sua violência intrínseca. O "universo encantado da criação pura”, como ironicamente o definiu Pascale Casanova em A república mundial das letras (2002), escamoteia os desafios da política literária, a existência de "guerras invisíveis” pelas "riquezas imateriais” do “capital Cultura”.

Como sugeriram Vladimir Voloshinov e Dominique Maingueneau, a obra parece só fazer sentido na medida em que reflete e refrata a vida que a tornou possível.

São escritas que modificam o estatuto tanto da literatura quanto do próprio cotidiano enquanto textualidade. São pós-autônomas porque atravessam a fronteira da literatura e da 
Pontos de Interrogação, v. 3, n. 1, jan./jul. 2013

Revista do Programa de Pós-Graduação em Crítica Cultural

Universidade do Estado da Bahia (UNEB), Campus II - Alagoinhas - BA

ficção. Porque tornam indecidível o limite entre textualidade e realidade, que definia a literatura moderna, “fabricam o presente com a realidade cotidiana e essa é uma das suas políticas” (LUDMER, 2007, p. 7).

A realidade cotidiana não é a realidade histórica referencial e verossímil do pensamento realista e da história política e social (a realidade separada da ficção), mas sim uma realidade produzida e construída pelos meios, pelas tecnologias e pelas ciências (LUDMER, 2007, p. 13).

Talvez seja por isso que Beatriz Resende (2008) afirmou que o viés político tende a atravessar todas as atividades na América Latina de hoje. É o fim de uma época em que a literatura define a si mesma como campo autônomo e unificado. É a morte da autonomia do literário e da auto-referencialidade.

A literatura nunca esteve tão viva, e tão em boas mãos: a dos muitos. Os muitos se vingam disseminando, borrando, reescrevendo, tornando cada vez mais públicos os procedimentos do literário, na propaganda, na tv e na música popular de massa, no cine, nos livros de auto-ajuda, nos quadrinhos, nos muitos tons, às vezes tão poucos, dos mais vendidos.

Em outras palavras: a perda da autonomia e da literariedade do literário é um signo de sua potência, agora enquanto força centrífuga da multidão. A perda da autonomia é parte de processos de singularização, de autonomias provisórias outras e estratégias pontuais e específicas, étnicas, de classe, de região, de geração, de gênero..., que delimitam e constrangem a escrita da escritura desde dentro.

Nas palavras de Susana Scramin (2007, p. 12), “é aquela que assume o risco inclusive de deixar de ser literatura, ou ainda, de fazer com que a literatura se coloque num lugar outro, num lugar de passagem entre os discursos”.

A potência da literatura de multidão encarna, como utopia assumidamente utópica, um devir-Brasil do mundo e um devir-mundo do Brasil, MundoBraz, nas belas palavras de Giuseppe Cocco colhidas em Antonio Negri e Eduardo Viveiros de Castro:

\footnotetext{
MundoBraz corresponde à "descoberta da miséria mais total que explode em direção à luz, ao Messias” (NEGRI, 2007, p. 32). MundoBraz, na medida em que a cosmologia da libertação encontra a materialíssima "nova imanência" da cosmologia ameríndia, com sua "internalização" de uma natureza que "não pode ser o nome do que está fora, pois não há fora, nem dentro" (VIVEIROS DE CASTRO, 1992, p. 15), e abre-se ao terreno da criação, da significação do mundo (COCCO, 2009, p. 20).
} 
A literatura de multidão, e sua pós-autonomia, “abre-se ao terreno da criação, da significação do mundo”, para além da literatura, sem deixar de tê-la, nunca, como horizonte próximo e instigante.

Para Cocco (2009, p. 37), o Brasil metaforiza a “ontologia” negativa da globalização, que suprime toda "forma-mundo do mundo" e submete as formas de vida ao risco constante de precarização e de fragmentação, de perda da capacidade de acolhimento e abertura.

Também a periferização do mundo pela tremenda desigualdade generalizante ampliada pela precarização da luta dos trabalhadores com o enfraquecimento do espaço da fábrica e dos sindicatos. Segregação espacial: favelização e condomínios fechados, explosão multipolar e dessolidarização (COCCO, 2009, p. 35).

A favela como metonímia da "brasilianização do mundo” supostamente é, como sugeriria um misto de Mike Davis e Giorgio Agamben, um “campo de concentração, “novo despotismo de um mundo reduzido a um único e inevitável futuro” (COCCO, 2009, p. 49).

Mas por isso mesmo, o Brasil encarna sua contraparte e engendra o contra-discurso exemplar pós-capitalista na medida em que hibridiza as "mil folhas que constituem os múltiplos planos da globalização” (COCCO, 2008, p. 42). Ruptura com a tradição colonial e póscolonial e recusa à imagem linear de futuro das sociedades ocidentais, presumida pelo capital e pelo progresso.

Narrativas de "um tempo novo qualificado", temporalidade intensiva e espacialidade horizontalizante. Imanência e estratos; consistência e organização. Processos de homo e heterogeneização (COCCO, 2009, p. 54).

Um espaço de intensificação de trocas e de práticas de resistência e produção, material e imaterial, dos pobres contra as formas de subordinação e rebaixamento. Potência de diferenciação e resistência.

É sob este aspecto que Beatriz Resende trata de uma literatura da multiplicidade, cuja preocupação com o presente contrasta com um momento anterior, de valorização da história e do passado, quer pela força e a importância político-estratégica do romance histórico, quer por manifestações de ufanismo em relação a momentos de construção da identidade nacional (RESENDE, 2008, p. 27). 
É sob o signo de uma multiplicidade ambivalente, antropofágica e autofágica, que estamos vivendo, capaz de tanto recusar os modos dominantes de produção de escritas associados à literatura quanto incorporar a todos.

É a intensidade da vida na metrópole hostil que se entranha nos universos privados, se imiscui na beleza achatada da propaganda luminescente do monitor de vídeo, até o espaço sem privacidade da vida doméstica, no espaço do trabalho e do lazer.

Toda visada apriorística sobre a literatura brasileira contemporânea, em particular ao que estou chamando de literatura de multidão, é um encontro tácito com o equívoco. É preciso cada vez mais deixar as obras falarem, naquilo que elas têm de não dito não emoldurável.

O crítico não deve esquecer as ferramentas e máquinas de produção de sentido que trouxe da longa tradição da literatura, mas só deve usá-las a posteriori, aceitando o risco de nenhuma servir e ter que "comprar" outras, pois a multidão cada vez menos "reproduz" o mundo. "Fabricam-no", para operar aquela "reversão potente da significação geral do sistema de escravidão" (COCCO, 2009, p. 51). A literatura de multidão sempre tem como horizonte próximo, também, as formas de escravidão, e elas são muitas.

A multiplicidade ambivalente é da própria crítica, do próprio pensamento sobre a literatura, também constrangido, muitas vezes contra a própria vontade, a negociar com outras tantas mediações, outras histórias e outras demandas, intelectuais e políticas, cada vez mais próximas e inseridas desde dentro.

Toda obra tem que agora, como nunca antes, estar inserida na vida das culturas e na cultura das vidas.

\section{ORALIZAR O BRASIL}

Foi em Edouard Glissant que li a instigante sugestão de que comunidades culturais não hegemônicas "trabalham" para oralizar a literatura:

Penso que hoje trabalhamos no sentido de uma "oralização" da literatura - por um lado porque há poesias orais coletivas que se desenvolvem; por outro lado porque está havendo "oralização" das técnicas da escrita (GLISSANT, 2006, p. 126). 
A oralização tem dupla face ou dois caminhos que se bifurcam, uma por ser coletiva e ter um pé nas memórias comunitárias, outra por ter com a escrita uma relação de hibridização e ruptura. Ela tem um aspecto imaginário, cultural, semiótico em toda amplitude; e um aspecto, diria, maquínico, tecnológico.

É a consciência maquínica das economias do signo que diferencia a oralização da oralidade, cuja relação com a ideologia do estado-nação devemos ter sempre em mente. Os pressupostos da oralidade estão na raiz de toda ideologia nacionalista na medida em que dela descende o próprio conceito de povo e de popular, por extensão, de nação.

A oralização é não nacionalista, é uma espécie não épica de epos, multilíngue e compósito, um epos que não crê no épico nem em sua epopeia. Ela é epos em 2 outros sentidos: na premissa da partilha e do comum, aquilo que, como sugeriu Jacques Rancière (2009), nos une e nos divide; e numa preocupação com os mortos e com suas memórias, constituídas, tradicionais, e por inventar, abertas, não absolutas, não solipsistas.

Por isso que pensar em oralização não é pensar em oralidade. A oralidade é um sistema estático; a oralização é errática, não sistemática e até caótica no sentido que está inserida na multiplicidade das culturas e de seus devires não previsíveis.

A oralização tem um pé fora da oralidade porque se situa sempre em contextos de escritas, muitas escritas e escritas de muitos. Ela possui uma relação indissociável com o letramento e com as muitas formas institucionais de uso da escrita, cada dia mais associada às máquinas de produção simbólica multimodais e intergenéricas. A própria escrita na oralização se constitui como uma máquina altamente tecnologizada.

Pensando nas comunidades africanas e em certo sentido na longa tradição de oralização da literatura nas literaturas africanas, Jean Derive nos dá boas pistas para pensá-la como espaço político estratégico para as comunidades não hegemônicas preservar sua memória e dos seus, expandir suas formas de produção simbólica para alhures, num processo que pressupõe uma reflexão constante sobre o próprio escrever:

Enquanto autênticos representantes de uma civilização de oralidade é que os escritores africanos produziram a literatura mais concordante com a suas normas escritas e que, ao contrário, é na mesma medida em que eles se integraram a uma civilização da escrita que eles tiveram os meios de operar a oralização dessa literatura. Pois, se admitimos a hipótese aqui defendida, trata-se exatamente de uma oralização da literatura, isto é, da operalização de um processo que supõe um trabalho. Mais do que índices naturalmente dispostos no texto, quase sem o conhecimento dos criado- 
Pontos de Interrogação, v. 3, n. 1, jan./jul. 2013

Revista do Programa de Pós-Graduação em Crítica Cultural

Universidade do Estado da Bahia (UNEB), Campus II - Alagoinhas - BA

res, as marcas de oralidade são signos, a serviço de estratégias - conscientes ou inconscientes que devem ser pensadas como efeitos de texto. Não há traços de oralidade, mas efeitos de oralidade (DERIVE, 2010, p. 24).

Se a oralização não pode esquecer nunca os estudos da oralidade, com ela não deve se confundir. A oralidade já tem uma longa tradição de pesquisa, é um conceito que constitui sistema, porque já possui, tanto na linguística quanto na antropologia e nos estudos literários, por exemplo, importantes bases de pesquisa para se pensar a voz e seus devires, mas é diferente da oralização porque esse sistema está eivado de pressupostos que o conceito de oralização recusa, a saber:

1) uma prática de memória associada a tradições supostamente uniformes e monodiscursivas, “populares”, muito arraigadas lá atrás, num passado absoluto;

2) a fala como princípio definidor, cuja anterioridade temos bons motivos para desacreditar, a oralização é mais sonora que linguageira, é escritura de rastros, para lembrar a crítica de Jacques Derrida ao fonologismo;

3) uma maneira de delimitar o objeto de pesquisa a partir de unidades estáveis, campos autônomos e exclusividade sociossemiótica.

Numa perspectiva que leva em conta as máquinas de produção de linguagem contemporâneas, Félix Guattari ajuda a pensar a oralização para além da oralidade a partir de num novo conceito de subjetividade nas sociedades contemporâneas associada a componentes sociais, “industriais” e semióticos a-significantes, formando "máquinas informacionais de signos, funcionando paralelamente ou independentemente, pelo fato de produzirem e veicularem significações e denotações que escapam então às axiomáticas propriamente lingüísticas” (GUATTARI, 1992, p. 14).

Para ele, subjetividade é

O conjunto das condições que torna possível que instâncias individuais e/ou coletivas estejam em posição de emergir como território existencial auto-referencial, em adjacência ou em relação de delimitação com uma alteridade ela mesma subjetiva (GUATTARI, 1992, p. 19).

Tendo como dois inimigos úteis a palavra e a música, a poesia sonora reage contra o fechamento operado pela linguagem, pratica uma comunicação fora da linguagem, pois se alimenta, conforme Félix Guattari, de processos de significação de diversas ordens: materiais e 
energéticos, de humor e afeto, representações mentais individuais e coletivas, “máquinas” desejantes e “máquinas” abstratas.

Portanto, subjetividade não remete a sujeito ou individualidade, ela é no mais das vezes coletiva. Se a fala plena da metafísica da presença esvazia "as dimensões existenciais da expressão”, exprimir tais dimensões exige uma máquina assignificante, que desterritorialize a essencialidade do nome e do sujeito identitário que funda a oralidade enquanto presença a si.

É no cruzamento de universos maquínicos heterogêneos, de dimensões diferentes, de textura ontológica estranha, com inovações radicais, sinais de maquinismos ancestrais outrora esquecidos e depois reativados, que se singulariza o movimento da história (GUATTARI, 1992, p. 53).

Sob este aspecto, a poesia sonora é antes um exercício e um processo em devir, em via de encontrar uma forma, como sugeriu um tanto idealisticamente Paul Zumthor, sem nunca efetivamente se “conformar”. Suas duas recusas históricas, da música e da palavra, objetivam a contribuição de "fluxos indiferenciados”, conforme Zumthor.

Diante dela, o leitor da escrita literária tradicional perde a segurança de seu espaço corporal unificante, ele não sabe onde pôr os olhos. As nossas faculdades de delimitação ordenadora do espaço se perdem, não importa tanto encontrar o significado das palavras... A oralização questiona a tirania dos signos que se impõem como única realidade.

Na oralidade maquínica, uma das muitas formas de oralização, nenhum conteúdo da subjetividade está imune à influência de diversos sistemas, que não são sinônimos da chamada sociedade das máquinas ou do virtual, pois as máquinas sempre estiveram, e em toda parte.

A voz de qualquer suposto poeta de primeira primeiridade só é possível em um ambiente maquínico: são máquinas tudo o que dá pertinência, existência e potência. Como sugeriu Leroi-Gourhan, um objeto não é nada fora do conjunto a que pertence, de seu "agenciamento maquínico de enunciação”.

A oralização, portanto, não articula (só ou principalmente) questões de identidade. Sua inserção num passado, numa tradição, numa comunidade, não para aí, no "identitário”. Como estratégia de leitura, o tempo é sempre o presente, “carregado de agoras”. De resíduos, contemporâneos não contemporâneos, potenciais formas por vir.

Ela não porta nenhuma saudade, todos os seus mortos estão vivos, no presente da obra. Não é o passado ou a memória de uma outra semiose em uma obra do presente do leitor, é 
Pontos de Interrogação, v. 3, n. 1, jan./jul. 2013

Revista do Programa de Pós-Graduação em Crítica Cultural

Universidade do Estado da Bahia (UNEB), Campus II - Alagoinhas - BA

uma espécie de futuro do texto atual, na medida em que não remete a um antes fundado lá atrás, só pode ser encontrada a posteriori, como “efeito”.

Se o romance é um gênero que reflete a forma de percepção intergenérica da modernidade, como queria Mikhail Bakhtin, associado à leitura silenciosa do livro, a oralização é intermidial. Ela não é encontrável só nas formas da interação vocal. Ela é tanto o devir da literatura para outras linguagens quanto a permanência, em nova base, da literatura como gênero do discurso moderno nas outras mídias e artes.

A oralização está associada a um novo élan cultural pós-romanesco que vai da literatura para tantas mídias e destas para o texto literário, sobretudo narrativo. Essa dominante cultural não é oral; é também oral, mas é principalmente sonora, para mim mais definidora do contemporâneo do que o imagético e ou visual tão comuns no discurso pós-moderno.

Se um dos pressupostos da teoria contemporânea é o de que vivemos num mundo de imagens, pouco se tem dito que a "imagem contemporânea”, seja lá o que isso for, aparece no mais das vezes acompanhada da voz e do som, ou seja, a imagem contemporânea é fortemente acústica.

Em algumas narrativas contemporâneas o graffite, a música popular em geral e o rap em particular, a televisão e a conversa cotidiana são mais determinantes que as tradições do livro e da leitura. A esfera acústica faz a escrita, a Literatura (com L maiúsculo), ser habitada por uma outra semiosfera, por um cruzamento diagonal do sonoro no livro.

Oralizar redimensiona o habitus linguageiro, institucional e excludente, e coloca a nossa disposição outras formas de formar, outras estruturas, outro tipo de signo e de interação sociodiscursiva, outros lugares de dizer e do fazer, sempre pela língua e pela escrita, nunca sem elas, mas não confinado a elas.

Trata-se de uma pulsão que atravessa a escrita e a oralidade numa relação de diálogo, fusão, tensão, pastiche, incorporação, comentário, citação, relação não “interlingual”, inter e intrassistêmica, pressupondo a literatura e suas escritas sempre num contexto de multiplicidades. Nem fora nem dentro, todas as linguagens, todas as mídias e todas as artes se atravessam. Em todo lugar só há barroquismo e crioulização. 
A oralização tem a toda vez um prefixo inter... e só se interessa por escritas, no sentido derrideano de rastros, materialidades de grama. A oralização, como a estou pensando aqui, está mais próxima da escrita que da oralidade. Sua relação com a oralidade é lateral, com a escrita é umbilical.

Com a urgência do cotidiano contra a opressão e o empobrecimento, a oralização pressiona o discurso constituinte da literatura como campo literário autônomo a tornar-se multiacentual e polivocal. Nas palavras de Robert Stam (1993, p. 156):

Enquanto a classe dominante luta por tornar o signo "uniacentual” e dotado de um caráter eterno e supraclassista, os oprimidos, especialmente quando têm consciência de sua opressão, lutam por arranjar a linguagem em prol de sua libertação.

Em outras palavras, oralizar a literatura é semiotizar a resistência dos muitos, de seus diversos modos de produção de linguagem e de vida através de um atravessar da escrita pelo sonoro, aquilo que define a nossa época e é a matriz de linguagem das maiorias minoritárias.

\section{REFERÊNCIAS}

COCCO, Giuseppe. MundoBraz: o devir-mundo do Brasil e o devir-Brasil do mundo. Rio de Janeiro: Record, 2009, p. 21-59.

DERIVE, Jean. Literarização da oralidade, oralização da literatura nas culturas africanas. In: Oralidade, literarização e oralização da literatura. Belo Horizonte: UFMG, 2010, p. 7-26.

GLISSANT, Edouard. O caos-mundo: por uma estética da relação. In: Introdução a uma poética da diversidade. Trad. Enilce Albergaria Rocha. Juiz de Fora: EDUFJF, 2005, p. 97-130.

GUATTARI, Félix. Caosmose: um novo paradigma estético. São Paulo: Editora 34, 1992.

LUDMER, Josefina. Literaturas pós-autônomas. Revista de Crítica Literaria y de Cultura, n. 17, jul. 2007. Disponível em: http://culturaebarbarie.org/sopro/n20.pdf.

MAINGUENEAU, Dominique. Um posicionamento na interlíngua. In: Idem. Discurso literário. São Paulo: Contexto, 2006, p. 180-195.

RANCIÈRE, Jacques. A partilha do sensível: estética e política. São Paulo: Editora 34, 2009.

REZENDE, Beatriz. A literatura brasileira na era da multiplicidade. In: Contemporâneos: expressões da literatura brasileira no século XXI. Rio de Janeiro: Casa da Palavra: Biblioteca Nacional, 2008, p. 15-41.

STAM, Robert. Mikhail Bakhtin e a crítica cultural de esquerda. In: KAPLAN, Ann (Org.). O mal-estar no pós-modernismo. Rio de Janeiro: J. Zahar Ed., 1993, p. 149-184.

ZUMTHOR, Paul. La poésie et le corps. In: Éscriture e nomadisme. Montreal: L’Hexagone, 1998. 
Pontos de Interrogação, v. 3, n. 1, jan./jul. 2013

Revista do Programa de Pós-Graduação em Crítica Cultural

Universidade do Estado da Bahia (UNEB), Campus II - Alagoinhas - BA

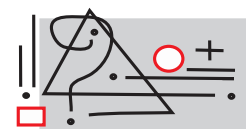

pontos de interrogaçă

SCRAMIN, Susana. Literatura do presente: história e anacronismo dos textos. Chapecó: Argos, 2007.

Recebido em: 25 de julho 2013.

Aprovado em: 15 de agosto de 2013. 
